\title{
Strong and $\Delta$-convergence theorems in hyperbolic spaces
}

\author{
Birol Gunduz and Sezgin Akbulut
}




\title{
STRONG AND $\Delta$-CONVERGENCE THEOREMS IN HYPERBOLIC SPACES
}

\author{
BIROL GUNDUZ AND SEZGIN AKBULUT
}

Received 6 June, 2013

\begin{abstract}
In this paper, we prove some strong and $\Delta$-convergence theorems for two finite families of nonexpansive maps on a hyperbolic space. Our iterative scheme is independent and simpler than the Ishikawa type iteration process. Our results refine and generalize several recent and comparable results in uniformly convex Banach spaces as well as CAT(0) spaces.
\end{abstract}

2010 Mathematics Subject Classification: 47H10; 49M05

Keywords: Kohlenbach hyperbolic space, $\Delta$-convergence, strong convergence, nonexpansive map, common fixed point

\section{INTRODUCTION}

Throughout this paper, $\mathbb{N}$ denotes the set of natural numbers and $I=\{1,2, \ldots, N\}$, the set of first $N$ natural numbers. Let $(X, d)$ be a metric space and $K$ be a nonempty subset of $X$. A selfmap $T$ on $K$ is said to be nonexpansive if $d(T x, T y) \leq d(x, y)$. Denote by $F(T)$ the set of fixed points of $T$ and by $F=\cap_{i=1}^{N}\left(F\left(T_{i}\right) \cap F\left(S_{i}\right)\right)$ the set of common fixed points of two finite families of mappings $\left\{T_{i}: i \in I\right\}$ and $\left\{S_{i}: i \in I\right\}$.

Given $x_{0}$ in $K$ (a subset of Banach space), Mann and Ishikawa iteration schemes for a mapping $T: K \rightarrow K$ read as follows:

$$
x_{n+1}=\left(1-\alpha_{n}\right) x_{n}+\alpha_{n} T x_{n},
$$

and

$$
\begin{aligned}
x_{n+1} & =\left(1-\alpha_{n}\right) x_{n}+\alpha_{n} T y_{n}, \\
y_{n} & =\left(1-\beta_{n}\right) x_{n}+\beta_{n} T x_{n},
\end{aligned}
$$

where $\left\{\alpha_{n}\right\}$ and $\left\{\beta_{n}\right\}$ are in $(0,1)$.

The concept of $\Delta$-convergence in general metric spaces was coined by Lim [18]. Kirk and Panyanak [14] specialized this concept to CAT(0) spaces and showed that many Banach space results involving weak convergence have precise analogs in this setting. Dhompongsa and Panyanak [5] continued to work in this direction and studied the $\Delta$-convergence of Picard, Mann and Ishikawa iterates in $C A T(0)$ spaces 
(Theorems 3.1, 3.2 and 3.3 respectively in [5]). While acknowledging their contribution, we note that their schemes involve one mapping. The case of two mappings in iteration schemes has also remained under study since Das and Debata [4] gave and studied a two mappings scheme on the pattern of the Ishikawa scheme:

$$
\begin{aligned}
x_{n+1} & =\left(1-\alpha_{n}\right) x_{n}+\alpha_{n} T x_{n}, \\
y_{n} & =\left(1-\beta_{n}\right) x_{n}+\beta_{n} S x_{n}, n \geq 1 .
\end{aligned}
$$

This scheme reduces to Ishikawa's scheme when $S=T$, and to Mann's Iteration scheme when $S=I$. In 2011, Khan and Abbas [11] obtained some results for two mappings using the Ishikawa-type iteration scheme (1.3) in $C A T(0)$ spaces. Note that the two mappings case, that is, approximating the common fixed points, has its own importance as it has a direct link with the minimization problem, see for example Takahashi [22].

On the other hand, let us state without error terms the iteration scheme studied by Yao and Chen [23] for common fixed points of two mappings:

$$
x_{n+1}=\alpha_{n} x_{n}+\beta_{n} T x_{n}+\gamma_{n} S x_{n},
$$

where $\left\{\alpha_{n}\right\},\left\{\beta_{n}\right\}$ and $\left\{\gamma_{n}\right\}$ are in $(0,1)$ and $\alpha_{n}+\beta_{n}+\gamma_{n}=1$.

We, in this paper, translate the iteration scheme (1.4) for two finite families of nonexpansive mappings in a subset $K$ of a hyperbolic space $X$ as under:

$$
x_{n+1}=W\left(T_{n} x_{n}, W\left(x_{n}, S_{n} x_{n}, \frac{\beta_{n}}{1-\alpha_{n}}\right), \alpha_{n}\right)
$$

where $T_{n}=T_{n}(\bmod N)$ and $S_{n}=S_{n}(\bmod N), 0<a \leq \alpha_{n}, \beta_{n} \leq b<1$ and satisfy $\alpha_{n}+\beta_{n}<1$.

Remark 1. It is worth mentioning that the iteration scheme (1.5) coincide with the iteration scheme (1.4) of Yao and Chen [23] when $W(x, y, \alpha)=\alpha x+(1-\alpha) y, S_{i}=$ $S$ and $T_{i}=T$ for all $i \in I$, and $X$ is a Banach space. Moreover, it provides iteration scheme of Abbas and Khan [1] in a CAT(0) space if $W(x, y, \alpha)=\alpha x \oplus(1-\alpha) y$ and $S_{i}=S, T_{i}=T$ for all $i \in I$.

Remark 2. Note that this scheme reduces to Mann's iteration scheme when either $S_{i}=T$ or $S_{i}=I$ or $T_{i}=I$ for all $i \in I$, and is independent and simpler than both the Ishikawa scheme and (1.3).

The aim of this article is to analyze $\Delta$-convergence as well as strong convergence through algorithm (1.5) for two finite families of nonexpansive maps in the more general setup of hyperbolic spaces. Our results can be viewed as refinement and generalization of several well-known results in $C A T(0)$ spaces and uniformly convex Banach spaces. 


\section{HYPERBOLIC SPACE}

We work in the setting of hyperbolic spaces as introduced by Kohlenbach [15]. It is worth noting that they are different from Gromov hyperbolic spaces [3] or from other notions of hyperbolic space that can be found in the literature (see for example $[7,13,19])$.

A hyperbolic space [15] is a triple $(X, d, W)$ where $(X, d)$ is a metric space and $W: X^{2} \times[0,1] \rightarrow X$ is such that

W1. $d(u, W(x, y, \alpha)) \leq \alpha d(u, x)+(1-\alpha) d(u, y)$

W2. $d(W(x, y, \alpha), W(x, y, \beta))=|\alpha-\beta| d(x, y)$

W3. $W(x, y, \alpha)=W(y, x,(1-\alpha))$

W4. $d(W(x, z, \alpha), W(y, w, \alpha)) \leq \alpha d(x, y)+(1-\alpha) d(z, w)$

for all $x, y, z, w \in X$ and $\alpha, \beta \in[0,1]$.

The convexity mapping $W$ was first considered by Takahashi in [21], where a triple $(X, d, W)$ satisfying (W1) is called a convex metric space (see, more details [8]). If $(X, d, W)$ satisfies (W1)-(W3), then we obtain the notion of space of hyperbolic type in the sense of Goebel and Kirk [7]. (W4) was already considered by Itoh [9] under the name "condition III" and it is used by Reich and Shafrir [19] and Kirk [13] to define their notions of hyperbolic space. Hyperbolic spaces are a natural generalization of both uniformly convex normed spaces and CAT( 0$)$ spaces.

A hyperbolic space $(X, d, W)$ is said to be uniformly convex [20] if for all $u, x, y \in$ $X, r>0$ and $\varepsilon \in(0,2]$, there exists a $\delta \in(0,1]$ such that

$$
\left.\begin{array}{r}
d(x, u) \leq r \\
d(y, u) \leq r \\
d(x, y) \geq \varepsilon r
\end{array}\right\} \Rightarrow d\left(W\left(x, y, \frac{1}{2}\right), u\right) \leq(1-\delta) r .
$$

A map $\eta:(0, \infty) \times(0,2] \rightarrow(0,1]$ which provides such a $\delta=\eta(r, \varepsilon)$ for given $r>0$ and $\varepsilon \in(0,2]$, is called modulus of uniform convexity. We call $\eta$ monotone if it decreases with $r$ (for a fixed $\varepsilon$ ).

Let $\left\{x_{n}\right\}$ be a bounded sequence in a hyperbolic space $X$. For $x \in X$, define a continuous functional $r\left(.,\left\{x_{n}\right\}\right): X \rightarrow[0, \infty)$ by $r\left(x,\left\{x_{n}\right\}\right)=\limsup _{n \rightarrow \infty} d\left(x, x_{n}\right)$. The asymptotic radius $\rho=r\left(\left\{x_{n}\right\}\right)$ of $\left\{x_{n}\right\}$ is given by $\rho=\inf \left\{r\left(x,\left\{x_{n}\right\}\right): x \in X\right\}$. The asymptotic center of a bounded sequence $\left\{x_{n}\right\}$ with respect to a subset $K$ of $X$ is defined as follows:

$$
A_{K}\left(\left\{x_{n}\right\}\right)=\left\{x \in X: r\left(x,\left\{x_{n}\right\}\right) \leq r\left(y,\left\{x_{n}\right\}\right) \text { for any } y \in K\right\} .
$$

The set of all asymptotic centers of $\left\{x_{n}\right\}$ is denoted by $A\left(\left\{x_{n}\right\}\right)$.

It has been shown in [17] that bounded sequences have unique asymptotic center with respect to closed convex subsets in a complete and uniformly convex hyperbolic space with monotone modulus of uniform convexity. 
A sequence $\left\{x_{n}\right\}$ in $X$ is said to $\Delta$-converge to $x \in X$ if $x$ is the unique asymptotic center of $\left\{u_{n}\right\}$ for every subsequence $\left\{u_{n}\right\}$ of $\left\{x_{n}\right\}$ [14]. In this case, we write $\Delta-\lim _{n} x_{n}=x$.

Recall that $\Delta$-convergence coincides with weak convergence in Banach spaces with Opial's property [16].

The proofs of the following two lemmas can be found in Khan et al. [10].

Lemma 1 ([10]). Let $(X, d, W)$ be a uniformly convex hyperbolic space with monotone modulus of uniform convexity $\eta$. Let $x \in X$ and $\left\{\alpha_{n}\right\}$ be a sequence in $[b, c]$ for some $b, c \in(0,1)$. If $\left\{x_{n}\right\}$ and $\left\{y_{n}\right\}$ are sequences in $X$ such that $\limsup _{n \rightarrow \infty} d\left(x_{n}, x\right) \leq r, \limsup _{n \rightarrow \infty} d\left(y_{n}, x\right) \leq r$ and $\lim _{n \rightarrow \infty} d\left(W\left(x_{n}, y_{n}, \alpha_{n}\right), x\right)$ $=r$ for some $r \geq 0$, then $\lim _{n \rightarrow \infty} d\left(x_{n}, y_{n}\right)=0$.

Lemma 2 ([10]). Let $K$ be a nonempty closed convex subset of a uniformly convex hyperbolic space and $\left\{x_{n}\right\}$ a bounded sequence in $K$ such that $A\left(\left\{x_{n}\right\}\right)=\{y\}$ and $r\left(\left\{x_{n}\right\}\right)=\rho$. If $\left\{y_{m}\right\}$ is another sequence in $K$ such that $\lim _{m \rightarrow \infty} r\left(y_{m},\left\{x_{n}\right\}\right)=\rho$, then $\lim _{m \rightarrow \infty} y_{m}=y$.

\section{STRONG AND $\Delta$-CONVERGENCE THEOREMS IN HYPERBOLIC SPACES}

Lemma 3. Let $K$ be a closed and convex subset of a hyperbolic space $X$ and let $\left\{T_{i}: i \in I\right\}$ and $\left\{S_{i}: i \in I\right\}$ be two finite families of nonexpansive selfmaps on $K$ such that $F \neq \varnothing$. Then for the sequence $\left\{x_{n}\right\}$ in (1.5), we have $\lim _{n \rightarrow \infty} d\left(x_{n}, p\right)$ exists for each $p \in F$.

Proof. Let $p \in F$. It follows from (1.5) that

$$
\begin{aligned}
d\left(x_{n+1}, p\right) & =d\left(W\left(T_{n} x_{n}, W\left(x_{n}, S_{n} x_{n}, \frac{\beta_{n}}{1-\alpha_{n}}\right), \alpha_{n}\right), p\right) \\
& \leq \alpha_{n} d\left(T_{n} x_{n}, p\right)+\left(1-\alpha_{n}\right) d\left(W\left(x_{n}, S_{n} x_{n}, \frac{\beta_{n}}{1-\alpha_{n}}\right), p\right) \\
& \leq \alpha_{n} d\left(x_{n}, p\right)+\beta_{n} d\left(x_{n}, p\right)+\left(1-\alpha_{n}-\beta_{n}\right) d\left(S_{n} x_{n}, p\right) \\
& \leq \alpha_{n} d\left(x_{n}, p\right)+\beta_{n} d\left(x_{n}, p\right)+\left(1-\alpha_{n}-\beta_{n}\right) d\left(x_{n}, p\right) .
\end{aligned}
$$

That is

$$
d\left(x_{n+1}, p\right) \leq d\left(x_{n}, p\right) .
$$

This gives that $\lim _{n \rightarrow \infty} d\left(x_{n}, p\right)$ exists for each $p \in F$.

We need the following lemma in order to prove some strong and $\Delta$-convergence theorems.

Lemma 4. Let $K$ be a closed and convex subset of a uniformly convex hyperbolic space $X$ with monotone modulus of uniform convexity $\eta$ and let $\left\{T_{i}: i \in I\right\}$ and 
$\left\{S_{i}: i \in I\right\}$ be two finite families of nonexpansive selfmaps on $K$ such that $F \neq \varnothing$. Then for the sequence $\left\{x_{n}\right\}$ in (1.5), we have

$$
\lim _{n \rightarrow \infty} d\left(x_{n}, T_{l} x_{n}\right)=\lim _{n \rightarrow \infty} d\left(x_{n}, S_{l} x_{n}\right)=0 \text { for each } l \in I .
$$

Proof. From Lemma 3, we know that $\lim _{n \rightarrow \infty} d\left(x_{n}, p\right)$ exists for each $p \in F$. We suppose that $\lim _{n \rightarrow \infty} d\left(x_{n}, p\right)=c$, that is,

$$
\lim _{n \rightarrow \infty} d\left(x_{n+1}, p\right)=\lim _{n \rightarrow \infty} d\left(W\left(T_{n} x_{n}, W\left(x_{n}, S_{n} x_{n}, \frac{\beta_{n}}{1-\alpha_{n}}\right), \alpha_{n}\right), p\right)=c
$$

Since $T_{n}$ is nonexpansive, we have $d\left(T_{n} x_{n}, p\right) \leq d\left(x_{n}, p\right)$ for each $p \in F$. Taking lim sup on both sides, we obtain

$$
\lim _{n \rightarrow \infty} d\left(T_{n} x_{n}, p\right) \leq c
$$

Observe that

$$
\begin{aligned}
d\left(W\left(x_{n}, S_{n} x_{n}, \frac{\beta_{n}}{1-\alpha_{n}}\right), p\right) & \leq \frac{\beta_{n}}{1-\alpha_{n}} d\left(x_{n}, p\right)+\left(1-\frac{\beta_{n}}{1-\alpha_{n}}\right) d\left(S_{n} x_{n}, p\right) \\
& \leq \frac{\beta_{n}}{1-\alpha_{n}} d\left(x_{n}, p\right)+\left(1-\frac{\beta_{n}}{1-\alpha_{n}}\right) d\left(x_{n}, p\right) \\
& =d\left(x_{n}, p\right)
\end{aligned}
$$

This gives

$$
\lim _{n \rightarrow \infty} d\left(W\left(x_{n}, S_{n} x_{n}, \frac{\beta_{n}}{1-\alpha_{n}}\right), p\right) \leq c .
$$

By using (3.1)-(3.3), and Lemma 1, we get

$$
\lim _{n \rightarrow \infty} d\left(T_{n} x_{n}, W\left(x_{n}, S_{n} x_{n}, \frac{\beta_{n}}{1-\alpha_{n}}\right)\right)=0 .
$$

Now

$$
\begin{aligned}
d\left(x_{n+1}, T_{n} x_{n}\right) & =d\left(W\left(T_{n} x_{n}, W\left(x_{n}, S_{n} x_{n}, \frac{\beta_{n}}{1-\alpha_{n}}\right), \alpha_{n}\right), T_{n} x_{n}\right) \\
& \leq \alpha_{n} d\left(T_{n} x_{n}, T_{n} x_{n}\right)+\left(1-\alpha_{n}\right) d\left(T_{n} x_{n}, W\left(x_{n}, S_{n} x_{n}, \frac{\beta_{n}}{1-\alpha_{n}}\right)\right)
\end{aligned}
$$

gives by (3.4) that

$$
\lim _{n \rightarrow \infty} d\left(x_{n+1}, T_{n} x_{n}\right)=0
$$

Moreover,

$$
\begin{aligned}
d\left(x_{n+1}, p\right) & =d\left(W\left(T_{n} x_{n}, W\left(x_{n}, S_{n} x_{n}, \frac{\beta_{n}}{1-\alpha_{n}}\right), \alpha_{n}\right), p\right) \\
& \leq \alpha_{n} d\left(T_{n} x_{n}, p\right)+\left(1-\alpha_{n}\right) d\left(W\left(x_{n}, S_{n} x_{n}, \frac{\beta_{n}}{1-\alpha_{n}}\right), p\right)
\end{aligned}
$$




$$
\begin{aligned}
& \leq \alpha_{n} d\left(x_{n}, p\right)+d\left(W\left(x_{n}, S_{n} x_{n}, \frac{\beta_{n}}{1-\alpha_{n}}\right), p\right) \\
& -\alpha_{n} d\left(W\left(x_{n}, S_{n} x_{n}, \frac{\beta_{n}}{1-\alpha_{n}}\right), p\right) \\
& \leq \alpha_{n} d\left(x_{n}, p\right)+d\left(W\left(x_{n}, S_{n} x_{n}, \frac{\beta_{n}}{1-\alpha_{n}}\right), p\right) \\
& -\alpha_{n}\left[\frac{\beta_{n}}{1-\alpha_{n}} d\left(x_{n}, p\right)+\left(1-\frac{\beta_{n}}{1-\alpha_{n}}\right) d\left(S_{n} x_{n}, p\right)\right] \\
& \leq \alpha_{n} d\left(x_{n}, p\right)+d\left(W\left(x_{n}, S_{n} x_{n}, \frac{\beta_{n}}{1-\alpha_{n}}\right), p\right) \\
& -\alpha_{n}\left[\frac{\beta_{n}}{1-\alpha_{n}} d\left(x_{n}, p\right)+\left(1-\frac{\beta_{n}}{1-\alpha_{n}}\right) d\left(x_{n}, p\right)\right] \\
& =d\left(W\left(x_{n}, S_{n} x_{n}, \frac{\beta_{n}}{1-\alpha_{n}}\right), p\right)
\end{aligned}
$$

yields that

$$
c \leq \lim \inf _{n \rightarrow \infty} d\left(W\left(x_{n}, S_{n} x_{n}, \frac{\beta_{n}}{1-\alpha_{n}}\right), p\right) .
$$

Combining (3.3) and (3.6), we have

$$
\lim _{n \rightarrow \infty} d\left(W\left(x_{n}, S_{n} x_{n}, \frac{\beta_{n}}{1-\alpha_{n}}\right), p\right)=c
$$

Again by Lemma 1 (with $\left.\limsup _{n \rightarrow \infty} d\left(S_{n} x_{n}, p\right) \leq c\right)$, we get

$$
\lim _{n \rightarrow \infty} d\left(x_{n}, S_{n} x_{n}\right)=0 \text {. }
$$

Furthermore,

$$
d\left(W\left(x_{n}, S_{n} x_{n}, \frac{\beta_{n}}{1-\alpha_{n}}\right), x_{n}\right) \leq \frac{\beta_{n}}{1-\alpha_{n}} d\left(x_{n}, x_{n}\right)+\left(1-\frac{\beta_{n}}{1-\alpha_{n}}\right) d\left(x_{n}, S_{n} x_{n}\right)
$$

gives by (3.8),

\section{Consider}

$$
\lim _{n \rightarrow \infty} d\left(W\left(x_{n}, S_{n} x_{n}, \frac{\beta_{n}}{1-\alpha_{n}}\right), x_{n}\right)=0
$$

$$
\begin{aligned}
d\left(x_{n+1}, x_{n}\right) & =d\left(W\left(T_{n} x_{n}, W\left(x_{n}, S_{n} x_{n}, \frac{\beta_{n}}{1-\alpha_{n}}\right), \alpha_{n}\right), x_{n}\right) \\
& \leq \alpha_{n} d\left(T_{n} x_{n}, x_{n}\right)+\left(1-\alpha_{n}\right) d\left(W\left(x_{n}, S_{n} x_{n}, \frac{\beta_{n}}{1-\alpha_{n}}\right), x_{n}\right) \\
& \leq \alpha_{n}\left\{d\left(x_{n+1}, x_{n}\right)+d\left(T_{n} x_{n}, x_{n+1}\right)\right\} \\
& +\left(1-\alpha_{n}\right) d\left(W\left(x_{n}, S_{n} x_{n}, \frac{\beta_{n}}{1-\alpha_{n}}\right), x_{n}\right) .
\end{aligned}
$$


From the above inequality, the following important inequality is obtained:

$$
d\left(x_{n+1}, x_{n}\right) \leq \frac{b}{1-b} d\left(T_{n} x_{n}, x_{n+1}\right)+d\left(W\left(x_{n}, S_{n} x_{n}, \frac{\beta_{n}}{1-\alpha_{n}}\right), x_{n}\right) .
$$

Taking limsup on both sides in the above inequality and then using (3.5) and (3.9), we have

$$
\lim _{n \rightarrow \infty} d\left(x_{n+1}, x_{n}\right)=0
$$

which implies that

$$
\lim _{n \rightarrow \infty} d\left(x_{n+l}, x_{n}\right)=0 \text { for } l<N .
$$

Since $d\left(x_{n}, T_{n} x_{n}\right) \leq d\left(x_{n}, x_{n+1}\right)+d\left(x_{n+1}, T_{n} x_{n}\right)$, therefore it follows from (3.5) and (3.10) that

$$
\lim _{n \rightarrow \infty} d\left(x_{n}, T_{n} x_{n}\right)=0
$$

For each $l \in I$, we have

$$
\begin{aligned}
d\left(x_{n}, T_{n+l} x_{n}\right) & \leq d\left(x_{n}, x_{n+l}\right)+d\left(x_{n+l}, T_{n+l} x_{n+l}\right)+d\left(T_{n+l} x_{n+l}, T_{n+l} x_{n}\right) \\
& \leq d\left(x_{n}, x_{n+l}\right)+d\left(x_{n+l}, T_{n+l} x_{n+l}\right)+d\left(x_{n+l}, x_{n}\right) \\
& \leq 2 d\left(x_{n}, x_{n+l}\right)+d\left(x_{n+l}, T_{n+l} x_{n+l}\right) .
\end{aligned}
$$

Thus, from (3.10) and (3.11), we have

$$
\lim _{n \rightarrow \infty} d\left(x_{n}, T_{n+l} x_{n}\right)=0 \text { for each } l \in I .
$$

Since the sequence $\left\{d\left(x_{n}, T_{l} x_{n}\right)\right\}$ is a subsequence of $\bigcup_{i=1}^{N}\left\{d\left(x_{n}, T_{n+l} x_{n}\right)\right\}$ and $\lim _{n \rightarrow \infty} d\left(x_{n}, T_{n+l} x_{n}\right)=0$ for each $l \in I$, therefore

$$
\lim _{n \rightarrow \infty} d\left(x_{n}, T_{l} x_{n}\right)=0 \text { for each } l \in I .
$$

For each $l \in I$, similar to the proof of (3.12), we have $\lim _{n \rightarrow \infty} d\left(x_{n}, S_{n+l} x_{n}\right)=0$ for each $l \in I$. Consequently, we obtain

$$
\lim _{n \rightarrow \infty} d\left(x_{n}, S_{l} x_{n}\right)=0 \text { for each } l \in I .
$$

The proof is completed.

Now we give $\Delta$-convergence theorems for two finite families of nonexpansive mappings.

Theorem 1. Let $K$ be a nonempty closed convex subset of a complete uniformly convex hyperbolic space $X$ with monotone modulus of uniform convexity $\eta$ and let $\left\{T_{i}: i \in I\right\}$ and $\left\{S_{i}: i \in I\right\}$ be two finite families of nonexpansive selfmaps on $K$ such that $F \neq \varnothing$. Then the sequence $\left\{x_{n}\right\}$ defined in (1.5), $\Delta$-converges to a common fixed point of $\left\{T_{i}: i \in I\right\}$ and $\left\{S_{i}: i \in I\right\}$. 
Proof. It follows from Lemma 3 that $\left\{x_{n}\right\}$ is bounded. Therefore $\left\{x_{n}\right\}$ has a unique asymptotic center, that is, $A\left(\left\{x_{n}\right\}\right)=\{x\}$. Assume that $\left\{u_{n}\right\}$ is any subsequence of $\left\{x_{n}\right\}$ such that $A\left(\left\{u_{n}\right\}\right)=\{u\}$. Then by Lemma 4, we have $\lim _{n \rightarrow \infty} d\left(u_{n}, T_{l} u_{n}\right)=$ $\lim _{n \rightarrow \infty} d\left(u_{n}, S_{l} u_{n}\right)=0$ for each $l=1,2, \cdots, N$. Now we prove that $u$ is the common fixed point of $\left\{T_{i}: i \in I\right\}$ and $\left\{S_{i}: i \in I\right\}$.

Define a sequence $\left\{v_{m}\right\}$ in $K$ by $v_{m}=T_{m} u$, where $T_{m}=T_{m}(\bmod N)$.

Clearly,

$$
\begin{aligned}
d\left(v_{m}, u_{n}\right) & \leq d\left(T_{m} u, T_{m} u_{n}\right)+d\left(T_{m} u_{n}, T_{m-1} u_{n}\right)+\cdots+d\left(T u_{n}, u_{n}\right) \\
& \leq d\left(u, u_{n}\right)+\sum_{i=1}^{m-1} d\left(u_{n}, T_{i} u_{n}\right) .
\end{aligned}
$$

Thus, we have

$$
r\left(v_{m},\left\{u_{n}\right\}\right)=\lim \sup _{n \rightarrow \infty} d\left(v_{m}, u_{n}\right) \leq \lim \sup _{n \rightarrow \infty} d\left(u, u_{n}\right)=r\left(u,\left\{u_{n}\right\}\right) .
$$

This implies that $\left|r\left(v_{m},\left\{u_{n}\right\}\right)-r\left(u,\left\{u_{n}\right\}\right)\right| \rightarrow 0$ as $m \rightarrow \infty$. By Lemma 2, we obtain $T_{m}(\bmod N) u=u$, which implies that $u$ is the common fixed point of $\left\{T_{i}: i \in I\right\}$. Similarly, we can show that $u$ is the common fixed point of $\left\{S_{i}: i \in I\right\}$. Therefore $u \in F$. Moreover, $\lim _{n \rightarrow \infty} d\left(x_{n}, u\right)$ exists by Lemma 3 .

Assume $x \neq u$. By the uniqueness of asymptotic centers,

$$
\begin{aligned}
\lim _{n \rightarrow \infty} d\left(u_{n}, u\right) & <\lim \sup _{n \rightarrow \infty} d\left(u_{n}, x\right) \\
& \leq \lim \sup _{n \rightarrow \infty} d\left(x_{n}, x\right) \\
& <\lim \sup _{n \rightarrow \infty} d\left(x_{n}, u\right) \\
& =\lim \sup _{n \rightarrow \infty} d\left(u_{n}, u\right)
\end{aligned}
$$

a contradiction. Thus $x=u$. Since $\left\{u_{n}\right\}$ is an arbitrary subsequence of $\left\{x_{n}\right\}$, therefore $A\left(\left\{u_{n}\right\}\right)=\{u\}$ for all subsequences $\left\{u_{n}\right\}$ of $\left\{x_{n}\right\}$. This proves that $\left\{x_{n}\right\}$ $\Delta$-converges to a common fixed point of $\left\{T_{i}: i \in I\right\}$ and $\left\{S_{i}: i \in I\right\}$.

Khan and Fukhar-ud-din [12], introduced the so-called condition (A') and gave a slightly improved version of it in [6] as follows:

Two mappings $T, S: K \rightarrow K$ with $F \neq \varnothing$ are said to satisfy the Condition (A') [12] if there exists a nondecreasing function $f:[0, \infty) \rightarrow[0, \infty)$ with $f(0)=0$, $f(t)>0$ for all $t \in(0, \infty)$ such that

$$
\text { either } d(x, T x) \geq f(d(x, F)) \text { or } d(x, S x) \geq f(d(x, F))
$$

for all $x \in K$, where $d(x, F)=\inf \{d(x, p): p \in F\}$.

We can modify this definition for two finite families of mappings as follows. Let $\left\{T_{i}: i \in I\right\}$ and $\left\{S_{i}: i \in I\right\}$ be two finite families of nonexpansive mappings of $K$ with nonempty fixed points set $F$. These families are said to satisfy Condition (B) 
on $K$ if there exists a nondecreasing function $f:[0, \infty) \rightarrow[0, \infty)$ with $f(0)=0$, $f(t)>0$ for all $t \in(0, \infty)$ such that

$$
\text { either } \max _{i \in I} d\left(x, T_{i} x\right) \geq f(d(x, F)) \text { or } \max _{i \in I} d\left(x, S_{i} x\right) \geq f(d(x, F))
$$

for all $x \in K$. The Condition (B) reduces to the Condition (A') when $T_{1}=T_{2}=\cdots=$ $T_{N}=T$ and $S_{1}=S_{2}=\cdots=S_{N}=S$ for all $i \in I$.

A sequence $\left\{x_{n}\right\}$ in a metric space $X$ is said to be Fejér monotone with respect to $K$ (a subset of $X$ ) if $d\left(x_{n+1}, p\right) \leq d\left(x_{n}, p\right)$ for all $p \in K$ and for all $n \geq 1$.

For further development, we need the following technical result.

Lemma 5 ([2]). Let $K$ be a nonempty closed subset of a complete metric space $(X, d)$ and $\left\{x_{n}\right\}$ be Fejér monotone with respect to $K$. Then $\left\{x_{n}\right\}$ converges to some $p \in K$ if and only if $\lim _{n \rightarrow \infty} d\left(x_{n}, K\right)=0$.

Lemma 6. Let $K$ be a nonempty closed convex subset of a complete uniformly convex hyperbolic space $X$ with monotone modulus of uniform convexity $\eta$ and let $\left\{T_{i}: i \in I\right\}$ and $\left\{S_{i}: i \in I\right\}$ be two finite families of nonexpansive selfmaps on $K$ such that $F \neq \varnothing$. Then the sequence $\left\{x_{n}\right\}$ defined in (1.5) converges strongly to $p \in F$ if and only if $\lim _{n \rightarrow \infty} d\left(x_{n}, F\right)=0$.

Proof. It follows from Lemma 3 that $\left\{x_{n}\right\}$ is Fejér monotone with respect to $F$ and $\lim _{n \rightarrow \infty} d\left(x_{n}, F\right)$ exists. Now applying the above Lemma, we obtain the result.

We use the Condition (B) to study strong convergence of $\left\{x_{n}\right\}$ defined in (1.5). It is worth noting that, in the case of two finite families of nonexpansive self mappings $\left\{T_{i}: i \in I\right\}$ and $\left\{S_{i}: i \in I\right\}$, the Condition (B) is weaker than the compactness of $K$.

Theorem 2. Let $K$ be a nonempty closed convex subset of a complete uniformly convex hyperbolic space $X$ with monotone modulus of uniform convexity $\eta$ and let $\left\{T_{i}: i \in I\right\}$ and $\left\{S_{i}: i \in I\right\}$ be two finite families of nonexpansive selfmaps on $K$ such that $F \neq \varnothing$. Suppose that $\left\{T_{i}: i \in I\right\}$ and $\left\{S_{i}: i \in I\right\}$ satisfy Condition $(B)$. Then the sequence $\left\{x_{n}\right\}$ defined in (1.5) converges strongly to $p \in F$.

Proof. By Lemma 3, $\lim _{n \rightarrow \infty} d\left(x_{n}, F\right)$ exists for all $p \in F$. Also, by Lemma 4, $\lim _{n \rightarrow \infty} d\left(x_{n}, T_{l} x_{n}\right)=\lim _{n \rightarrow \infty} d\left(x_{n}, S_{l} x_{n}\right)=0$ for each $l \in I$. It follows from Condition (B) that $\lim _{n \rightarrow \infty} f\left(d\left(x_{n}, F\right)\right)=0$. Since $f$ is nondecreasing with $f(0)=$ 0 , we have $\lim _{n \rightarrow \infty} d\left(x_{n}, F\right)=0$. Now, Theorem 6 implies that $\left\{x_{n}\right\}$ converges strongly to a point $p$ in $F$.

Although the following are corollaries to our Theorems 1-2, yet they are new in the literature.

Theorem 3. Let $K$ be a nonempty closed convex subset of a complete uniformly convex hyperbolic space $X$ with monotone modulus of uniform convexity $\eta$ and let $T$ 
and $S$ be two nonexpansive selfmaps on $K$ such that $F:=F(T) \cap F(S) \neq \varnothing$. Let the sequence $\left\{x_{n}\right\}$ defined by

$$
x_{n+1}=W\left(T x_{n}, W\left(x_{n}, S x_{n}, \frac{\beta_{n}}{1-\alpha_{n}}\right), \alpha_{n}\right)
$$

Then $\left\{x_{n}\right\} \Delta$-converges to a common fixed point of $\left\{T_{i}: i \in I\right\}$.

Proof. Choose $S_{i}=S$ and $T_{i}=T$ for all $i \in I$ in the theorem 1.

Theorem 4. Let $K$ be a nonempty closed convex subset of a complete uniformly convex hyperbolic space $X$ with monotone modulus of uniform convexity $\eta$ and let $T$ and $S$ be two nonexpansive selfmaps satisfying the Condition $\left(A^{\prime}\right)$ on $K$ such that $F:=F(T) \cap F(S) \neq \varnothing$. Then the sequence $\left\{x_{n}\right\}$ defined in (3.15) converges strongly to $p \in F$.

Remark 3. (1) Theorem 1 and Theorem 2 extends the corresponding results of Abbas and Khan [1] in two ways: (i) from two nonexpansive mappings to two finite families of nonexpansive mappings (ii) from $C A T(0)$ space to general setup of uniformly convex hyperbolic spaces.

(2) Theorem 1 sets analogue of [11, Theorem 1], for two finite families of nonexpansive maps on unbounded domain in a uniformly convex hyperbolic space $X$.

(3) Theorems 1-2 contain the corresponding theorems proved for the Mann iteration scheme when $S_{i}=I d$ or $T_{i}=I d$ ( $I d$ is the identity mapping) for all $i \in I$.

(4) In view of simplicity of the iterative process (1.5) as compared with (1.2) and (1.3), our results improve and generalize the results of Dhompongsa and Panyanak [5] and Khan and Abbas [11].

\section{REFERENCES}

[1] M. Abbas and S. H. Khan, "Some $\delta$-convergence theorems in cat(0) spaces," Hacet. J. Math. Stat., vol. 40, no. 4, pp. 563-569, 2011.

[2] H. H. Bauschke and P. L. Combettes, Convex analysis and monotone operator theory in Hilbert spaces, ser. CMS Books in Mathematics. Berlin: Springer, 2011.

[3] M. R. Bridson and A. Haefliger, Metric spaces of non-positive curvature, ser. Grundlehren der Mathematischen Wissenschaften. Berlin: Springer, 1999, vol. 319.

[4] G. Das and J. P. Debata, "Fixed points of quasinonexpansive mappings," Indian J. Pure Appl. Math., vol. 17, pp. 1263-1269, 1986.

[5] S. Dhompongsa and B. Panyanak, "On $\Delta$-convergence theorems in CAT(0) spaces," Comput. Math. Appl., vol. 56, no. 10, pp. 2572-2579, 2008.

[6] H. Fukhar-Ud-Din and S. H. Khan, "Convergence of iterates with errors of asymptotically quasinonexpansive mappings and applications," J. Math. Anal. Appl., vol. 328, no. 2, pp. 821-829, 2007.

[7] K. Goebel and W. A. Kirk, "Iteration processes for nonexpansive mappings," Contemp. Math., vol. 21, pp. 115-123, 1983.

[8] B. Gunduz and S. Akbulut, "Strong convergence of an explicit iteration process for a finite family of asymptotically quasi-nonexpansive mappings in convex metric spaces," Miskolc Math. Notes, Accepted. 
[9] S. Itoh, "Some fixed point theorems in metric spaces," Fundam. Math., vol. 102, pp. 109-117, 1979.

[10] A. R. Khan, H. Fukhar-ud-din, and M. A. A. Khan, "An implicit algorithm for two finite families of nonexpansive maps in hyperbolic spaces," Fixed Point Theory Appl., vol. 2012, p. 12, 2012.

[11] S. H. Khan and M. Abbas, "Strong and $\Delta$-convergence of some iterative schemes in CAT(0) spaces," Comp. Math. Appl., vol. 61, pp. 109-116, 2011.

[12] S. H. Khan and H. Fukhar-ud-din, "Weak and strong convergence of a scheme with errors for two nonexpansive mappings," Nonlinear Anal., Theory Methods Appl., Ser. A. Theory Methods, vol. 61, no. 8, pp. 1295-1301, 2005.

[13] W. A. Kirk, "Krasnoselskii's iteration process in hyperbolic space," Numer. Funct. Anal. Optim., vol. 4, pp. 371-381, 1982.

[14] W. A. Kirk and B. Panyanak, "A concept of convergence in geodesic spaces," Nonlinear Anal., Theory Methods Appl., Ser. A, Theory Methods, vol. 68, no. 12, pp. 3689-3696, 2008.

[15] U. Kohlenbach, "Some logical metatheorems with applications in functional analysis," Trans. Am. Math. Soc., vol. 357, no. 1, pp. 89-128, 2005.

[16] T. Kuczumow, "An almost convergence and its applications," Ann. Univ. Mariae CurieSktodowska, Sect. A, vol. 32, pp. 79-88, 1978.

[17] L. Leuştean, "Nonexpansive iterations in uniformly convex $w$-hyperbolic spaces," in Nonlinear analysis and optimization I. Nonlinear analysis. A conference in celebration of Alex Ioffe's 70th and Simeon Reich's 60th birthdays, Haifa, Israel, June 18-24, 2008, ser. Contemporary Mathematics. Providence, RI; Ramat-Gan: American Mathematical Society (AMS); Bar-Ilan University, 2010, vol. 513, pp. 193-210.

[18] T.-C. Lim, "Remarks on some fixed point theorems," Proc. Am. Math. Soc., vol. 60, pp. 179-182, 1977.

[19] S. Reich and I. Shafrir, "Nonexpansive iterations in hyperbolic spaces," Nonlinear Anal., Theory Methods Appl., Ser. A, Theory Methods, vol. 15, no. 6, pp. 537-558, 1990.

[20] T. Shimizu and W. Takahashi, "Fixed points of multivalued mappings in certain convex metric spaces," Topol. Methods Nonlinear Anal., vol. 8, no. 1, pp. 197-203, 1996.

[21] W. Takahashi, "A convexity in metric spaces and nonexpansive mappings," Kodai Math Sem Rep., vol. 22, pp. 142-149, 1970.

[22] W. Takahashi, "Iterative methods for approximation of fixed points and their applications," J. Oper. Res. Soc. Japan, vol. 43, no. 1, pp. 87-108, 2000.

[23] Y. Yao and R. Chen, "Weak and strong convergence of a modified Mann iteration for asymptotically nonexpansive mappings," Nonlinear Funct. Anal. Appl., vol. 12, no. 2, pp. 307-315, 2007.

\section{Authors' addresses}

\section{Birol Gunduz}

Current address: Department of Mathematics, Faculty of Science and Art, Erzincan University, Erzincan, 24000, Turkey.

E-mail address: birolgndz@gmail.com

\section{Sezgin Akbulut}

Current address: Department of Mathematics, Faculty of Science, Ataturk University, Erzurum, 25240, Turkey.

E-mail address: sezginakbuluteatauni.edu.tr 